\title{
A Cost Analysis of Four Benefit Strategies for Managing a Cox II Inhibitor
}

OBJECTIVE: To analyze the cost impact of celecoxib utilization and to determine which benefit strategy is the most effective in ensuring appropriate utilization of this product.

SETTING: Four client companies of a pharmacy benefit management company (PBM). The four clients examined varied in size, demographics, and benefit design.

DESIGN: Reports showing paid claims were run using prescription data software. Excel spreadsheet software was used to manipulate the data from the actual claims, substituting a theoretical benefit strategy for the actual. The results of the theoretical were then compared to the actual.

MAIN OUTCOME MEASURES: Cost savings achieved through four cost containment programs: requirement of a prior authorization in which the member's claim for celecoxib was previously rejected; contingent (step) therapy, in which other alternatives were tried and failed before use of celecoxib; a therapeutic buy-up program in which a maximum allowable cost is implemented with the member paying the difference; and a three-tiered copayment plan in which celecoxib is placed in the highest tier with other nonformulary medications.

RESULTS: The highest percentage savings $(\mathbf{7 4 . 1 \% )}$ was achieved through the step-therapy measure. Prior authorization resulted in savings of $49.8 \%$; therapeutic buy-up yielded savings of $36.8 \%$; and three-tier copayment resulted in savings of $17.1 \%$. All savings are based on the percentage saved by the plan over the amount the plan would have paid without these cost-containment measures in effect.

CONCLUSION: Step therapy provides the greatest savings in costs to health plans of the four measures examined.

KEYWORDS: Managed care organization, pharmacy benefits management, formularies, prescription cost containment, step therapy

J Managed Care Pharm 2001: 224-27

\section{Authors}

At the time this article was written, GREGORY TUCKER, Pharm.D., was a managed care resident with AdvancePCS in Richardson, TX; he is now a clinical pharmacist with BlueCross BlueShield of Texas. When this article was written, ANDREA MOORE, DEBORAH AVANT, and MERLYN MONTEIRO were pharmacists with AdvancePCS.

AUTHOR CORRESPONDENCE: Gregory Tucker, Pharm.D., BlueCross BlueShield of Texas, 901 S. South Central Expwy, N. Bldg, Mail Drop D, Richardson, TX 75080; Tel: 972-766-2722; Fax: 972-766-1656; E-mail. greg.tucker@bcbstx.com

Copyright $\odot 2001$ Academy of Managed Care Pharmacy, Inc. All rights reserved.
by Gregory Tucker, Andrea Moore, Deborah Avant, and Merlyn Monteiro

$\mathrm{T}$ raditional pain and arthritis medications, known as nonsteroidal anti-inflammatory agents (NSAIDS), inhibit the enzymes Cox I and Cox II. Cox I assists in the regulation of normal body processes, whereas Cox II is believed to play a role in pain and inflammation. Celecoxib was the first drug of its type to target only Cox II, and is available in 100 and $200 \mathrm{mg}$ capsules. For osteoarthritis, $100 \mathrm{mg}$ is given twice a day, and for rheumatoid arthritis, up to $200 \mathrm{mg}$ twice a day is prescribed. Celecoxib also was the first agent approved as an adjunct to usual care for familial adenomatous polyposis. The dose for familial adenomatous polyposis is 400 mg twice a day. ${ }^{1}$

Since its release in early 1999, celecoxib (branded as Celebrex) has become one of the most frequently prescribed medications for arthritis. Another Cox II inhibitor, Vioxx, is also indicated for the relief of chronic pain, stiffness, and inflammation associated with osteoarthritis; however, celecoxib was chosen for this study (conducted February-December 1999) because it was the first Cox II inhibitor available, had a more extensive list of chronic indications, and was more prevalent on managed care formularies.

Celecoxib is an expensive medication and has the potential for misuse and/or overuse. With the availability of other therapeutic options, many pharmacy benefit plans have chosen to place restrictions on celecoxib. Figure 1, page 225, shows a comparison of the cost per day of celecoxib therapy in relation to the daily cost of treatment with other NSAIDS.

This study examines the impact of celecoxib from the perspective of a pharmacy benefit management company (PBM), Advance Paradigm (API, now AdvancePCS). Many of the clients served by API, including those whose data were examined in this study, do not operate their own internal pharmacy departments and base their pharmacy benefit decisions on API's clinical expertise.

The objective of this study was to evaluate the impact of four benefit strategies on celecoxib utilization and to determine which was the most effective in ensuring appropriate use of this product. The major outcome measure was to report which of the following cost-containment programs resulted in the most significant cost savings to the plan:

- requirement of a prior authorization in which the member's claim for celecoxib was previously rejected;

- contingent (step) therapy, in which other alternatives were 
tried and failed before celecoxib was used;

- a therapeutic buy-up program, in which a maximum allowable cost is implemented with the member paying the difference; or

- a three-tiered copayment plan, in which celecoxib is placed in the highest tier with other nonformulary medications.

\section{Methods}

Reports showing paid claims were run using the Apothequery prescription data software, a patented API product. These reports, which contained data from four of API's clients, showed each claim processed, information about patient copayments, days supply, quantity dispensed, ingredient costs paid, the date each prescription was filled, and medication strength. For claims that were denied and never subsequently paid, requests were submitted to the information technology department for retrieval of these data. Claims that were submitted and subsequently reversed were "scrubbed" and discarded. Corresponding data reports were manipulated using Excel spreadsheet software when necessary. The four clients examined varied in size, demographics, and benefit design.

Data from a 36,000-member indemnity plan that uses a three-tiered copayment program were gathered and examined. The lowest tier, corresponding to generic drugs, requires a \$7 copayment. Preferred brand-name drugs, the second tier, require a $\$ 15$ copayment. Celecoxib is placed on the third tier, nonpreferred brand-name drugs, which requires a \$25 copayment. This type of program discourages use of nonpreferred drugs, but allows the patient access to the medication if he or she is willing to pay the price.

Using Excel software, all $\$ 25$ copayments were changed to $\$ 15$, thus showing a theoretical total copayment and a theoretical total amount paid had the third tier not been implemented. The difference between the theoretical amount paid and the actual amount paid was determined, and a percentage savings was calculated. The three-tier copayment saves this plan $17.1 \%$ compared to the amount that would have been paid had the third tier not been implemented.

Data from a 142,000-member group with a therapeutic buyup plan were gathered and examined. In this type of plan, the insurer selects a limited number of preferred products in a given therapeutic class. The member pays the difference between the cost of the nonpreferred product and the preferred product, plus the appropriate copayment. In order for a member to receive celecoxib, a nonpreferred product, the member must pay a $\$ 20$ copayment plus the difference of the cost of the medication, using generic naproxen as the comparison. Again, this discourages use of the drug, but allows access to patients willing to pay the price. Using Excel software, all copayments greater than $\$ 20$ were normalized to $\$ 20$, resulting in a theoretical total copayment and a theoretical total amount paid had the use of celecoxib not been restricted. The difference between the theoretical amount paid

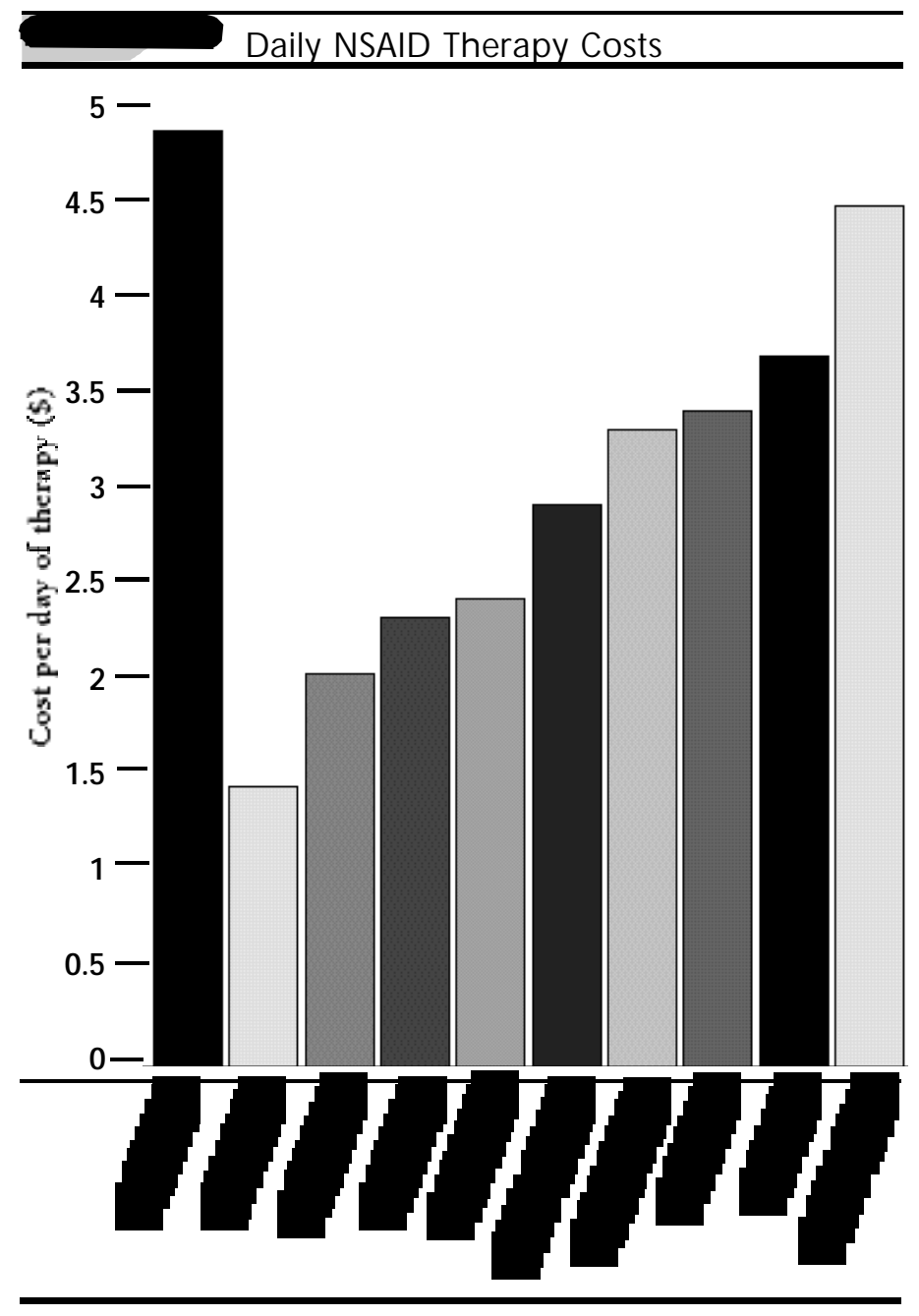

and the actual amount paid was determined, and a percentage of savings was calculated. The therapeutic buy-up program saves this plan $36.7 \%$ over what the plan would have paid if no restrictions were implemented.

Claims data were examined from a 46,000-member group that uses a prior-authorization program to control the use of celecoxib. In this type of program, pharmacists are trained in specific disease states and their appropriate treatments. They are responsible for determining whether celecoxib is being prescribed appropriately according to guidelines set by the plan, and approve or deny submitted claims accordingly. ${ }^{3}$ The prior-authorization requirements do not specify a diagnosis; however, they do outline specific screening criteria for patients who should not be on NSAIDs, based on factors such as increased age, risk of GI bleeding, use of anticoagulants, and previous intolerance to other NSAIDs. Data for appeals were not available or tracked by API.

Under this plan, celecoxib may be used by patients who:

- are older than 65; 


\begin{tabular}{|c|c|c|c|c|c|c|c|c|}
\hline $\begin{array}{c}\text { Cost- } \\
\text { Containment } \\
\text { Program } \\
\text { (Number of } \\
\text { Claims) }\end{array}$ & $\begin{array}{l}\text { Amount } \\
\text { Paid }\end{array}$ & Copayment & \multicolumn{2}{|c|}{$\begin{array}{l}\text { Days } \\
\text { Supply }\end{array}$} & Quantity & $\begin{array}{l}\text { Ingredient } \\
\text { Cost Paid }\end{array}$ & $\begin{array}{c}\text { Cost of } \\
\text { Approvals } \\
\text { Plus Denials }\end{array}$ & $\%$ Savings $^{a}$ \\
\hline $\begin{array}{l}\text { Step therapy } \\
\text { (138) }\end{array}$ & $\$ 7,661.14$ & $\$ 3,241.04$ & \multicolumn{2}{|c|}{3,970} & 4,907 & $\$ 10,285.45$ & $\$ 29,610.34$ & 74.1 \\
\hline $\begin{array}{c}\text { Prior } \\
\text { authorization } \\
(879)\end{array}$ & $\$ 64,922.61$ & $\$ 7,314.14$ & \multicolumn{2}{|c|}{25,356} & 37,851 & $\$ 69,745.51$ & $\$ 129,443.25$ & 49.8 \\
\hline $\begin{array}{c}\text { Cost- } \\
\text { Containment } \\
\text { Program } \\
\text { (Number of } \\
\text { Claims) }\end{array}$ & $\begin{array}{l}\text { Amount } \\
\text { Paid }\end{array}$ & Copayment & $\begin{array}{l}\text { Days } \\
\text { Supply }\end{array}$ & Quantity & $\begin{array}{l}\text { Ingredient } \\
\text { Cost Paid }\end{array}$ & $\begin{array}{c}\text { New } \\
\text { Copayment }\end{array}$ & $\begin{array}{l}\text { New } \\
\text { Paid }\end{array}$ & $\%$ Savings ${ }^{b}$ \\
\hline $\begin{array}{c}\text { Therapeutic } \\
\text { buy-up }(8,989)\end{array}$ & $\$ 412,368.55$ & $\$ 385,887.39$ & 296,883 & 415,421 & $\$ 775,304.44$ & $\$ 145,813.75$ & $\$ 652,442.19$ & 36.18 \\
\hline $\begin{array}{l}\text { Three-tier co- } \\
\text { payment (505) }\end{array}$ & $\$ 23,019.98$ & $\$ 12,426.25$ & 13,480 & 17,925 & $\$ 34,301.91$ & $\$ 7,695.00$ & $\$ 27,751.23$ & 17.10 \\
\hline \multicolumn{5}{|c|}{ \% savings calculation: (Cost of approvalstdenials)- amount paid } & \multicolumn{3}{|c|}{${ }^{\%} \%$ savings calculation: $\mathrm{N}$ ew paid-amount paid } & \\
\hline \multicolumn{5}{|c|}{ Cost of approvals+denials } & \multicolumn{3}{|c|}{ New paid } & \\
\hline
\end{tabular}

- have prior documentation of GI ulcer;

- are concurrently treated with corticosteroids or anticoagulants;

- have used an $\mathrm{H}_{2}$ blocker or proton pump inhibitor;

- are smokers or alcohol abusers; and/or

- have tried and demonstrated intolerance of at least two other NSAIDS.

A comparison was made between celecoxib claims that were paid and those claims that were submitted but denied payment. The cost per unit of therapy (capsule) was calculated by dividing the total amount paid by the plan by the total number of capsules dispensed. A listing of all celecoxib claims that were ultimately rejected was obtained, and the total number of capsules that were not dispensed was also calculated. Using the cost per capsule, cost savings were determined. The cost savings were then compared with the potential total amount paid (paid claims plus rejected claims). The total savings was $49.8 \%$.

The final group studied is a plan with 13,000 lives that has implemented a step-therapy program. Step therapy is similar to prior authorization; predetermined requirements are established and the computer system will automatically pay the submitted claim if, within the previous 90 days, the patient has used at least one of the following for 30 days:

- Cox II inhibitor or NSAID;

- $\mathrm{H}_{2}$ antagonist, proton pump inhibitor, Cytotec (prostaglandin), sucralfate;

- anticoagulant/antiplatelet therapy; or

- 10 days of combination ulcer treatment (i.e., PrevPac).

As with prior authorization, a comparison was made between all paid celecoxib claims and all celecoxib claims that were submitted but denied payment. A total for all submitted celecoxib claims, regardless of final payment status, was determined. The percentage of savings was calculated to be $74.1 \%$. Step therapy is the program that realizes the largest percentage in cost savings of the plans examined (see Table 1, above).

\section{- Limitations}

Certain inherent limitations and assumptions must be addressed concerning this analysis and the methods used. Ideally, data for such an analysis would be collected over a two-year period. Celecoxib was released during the first quarter of 1999; therefore, only several months' (February-December 1999) worth of data could be examined.

The software used to obtain claims data, Apothequery, has two main limitations that must be considered. First, integration of the program with other software is difficult, and at the time this article was written, the database was updated only every 30 days. The software used to manipulate and examine the data is limited in the number of records it will hold at one time, lead- 
ing to additional steps in the data-examination process. Such piecemeal examination of the data allows for an increased margin of error in calculations. A fairly thorough knowledge of the syntax of the software is necessary in order to perform the necessary statistical manipulations of the data. Assumptions were made that the data received were accurate and correct, and that celecoxib was being prescribed correctly (i.e., for indications discussed previously, and not for chronic pain).

Administrative fees and transmission costs were not included due to their variability from plan to plan. Differences in demographics among patient populations were not considered. The focus of this study was to determine which benefit design was the most cost-effective; however, because of the lack of availability of diagnostic information, cost differences between dosages had to be omitted.

Certain biases must be addressed from the perspective of the PBM. These companies, like any other for-profit organizations, must make money in order to succeed. PBMs are faced with the challenge of reducing drug costs for their clients while maintaining a high standard of care for their clients' members. PBMs must negotiate with pharmaceutical manufacturers to keep medication costs as low as possible, while keeping the patient's best interest as their top priority.

Step therapy shows the biggest cost savings to a plan; how- ever, the actual amount of this savings may be over-inflated because of the small size of the plan used as an example.

\section{Conclusion}

Since its release in early 1999, celecoxib has become one of the most widely prescribed drugs for arthritis, and has since been awarded the additional indication of familial adenomatous polyposis. Celecoxib was the first member of the new class of drugs known as Cox II inhibitors, and was marketed as a drug that would reduce $\mathrm{GI}$ effects that other NSAIDs cause.

$M$ any PBMs and health benefit plans have addressed the high cost and potential for misuse of celecoxib and have placed restrictions on its use by implementing various methods of control. Despite the limitations mentioned, it can be concluded that step therapy provides a plan the greatest amount of cost avoidance because it is the most restrictive of the cost savings measures examined.

\section{References}

1. Celebrex Package Insert, Pfizer, 1999.

2. 1999 Drug topics redbook, Feb. 2000 Update.

3. Wertheimer Al, Navarro RP. Managed care pharmacy principles and practice. N ew York: Pharmaceutical Products Press, 1999, 303-04. 